\title{
Studies of the life-history and energetics of marine and brackish-water nematodes
}

\section{Demography of Monhystera disjuncta at different temperature and feeding conditions}

\author{
G. Vranken ${ }^{1}$, P.M.J. Herman ${ }^{2}$, and C. Heip ${ }^{2}$ \\ ${ }^{1}$ Marine Biology Section, Zoology Institute, State University of Gent, Ledeganckstraat 35, B-9000 Gent, Belgium \\ ${ }^{2}$ Delta Institute for Hydrobiological Research, Vierstraat 28, NL-4401 EA Yerseke, The Netherlands
}

\begin{abstract}
Summary. Aspects of the demography of Monhystera disjuncta were investigated at different temperatures (in agnotobiotic cultures) and in different feeding conditions (monoxenic cultures with different bacterial strains, and different densities in the feeding suspension with one strain). Embryonic development time, minimum generation time, egg deposition rate and adult longevity depend on temperature, quality and quantity of food offered. Body mass at maturity is an allometric function of food density. It is shown that a previously inferred selectivity in food uptake is an artifact of culture conditions. $\mathrm{pH}$ buffering and addition of sterols permit culture of the species on a wide variety of bacterial strains. $M$. disjuncta is less well adapted to take advantage of high food density than are nematodes from polysaprobic environments. The animals channel surplus energy intake into a larger body mass, without being able to increase their rate of population growth accordingly.
\end{abstract}

Key words: Nematodes - Demography - Feeding Meiobenthos - Culture

Nematodes constitute an important fraction of the meiofauna in marine sediments. Yet, they have not always received the attention they deserve. In particular, their role in energy transfer in the sediment ecosystem and their importance as food for higher trophic levels remains unestablished (Heip et al. 1985).

Experimental studies point to an important contribution of nematodes in stimulating the breakdown of detritus (Abrams and Mitchell 1980; Findlay and Tenore 1982; Tietjen 1980). However, more recent observations seem to question this aspect too, at least for conditions of high detritus stocks (Alongi 1985a, b).

For the study of nematode productivity, we are entirely dependent on laboratory experiments. Production of field populations is extremely difficult to measure, as almost all populations have continuous reproduction. In previous publications (Heip et al. 1985; Herman et al. 1984; Vranken et al. 1986; Vranken and Heip 1986) we approached the problem of nematode productivity in several indirect ways. These approaches were based on data obtained from agnotobiotic nematode cultures (i.e. cultures in which the composition of the food is not controlled). Although food was believed to be offered in excess, no explicit study was made about the importance of its quality or quantity.

Offprint requests to: P.M.J. Herman
In this paper we shall discuss the demography of Monhystera disjuncta, cultured at different temperatures and in different feeding conditions. Demographic data from agnotobiotic cultures at $12^{\circ} \mathrm{C}$ were already given by Vranken and Heip (1986). They will be completed by data obtained at $3^{\circ} \mathrm{C}$ and $17^{\circ} \mathrm{C}$. For the purpose of bio-assay studies a monoxenic culture method of this species was developed using Alteromonas haloplanktis (strain "ISC2") as a food source. This change in culture conditions was reflected in the demographic parameters (Vranken et al. 1984).

Density of the bacterial food is known to be a major determinant for the life cycle of bacterivorous nematodes. Schiemer (1982a, b, 1983), Schiemer et al. (1980) and Klekowski et al. (1979) studied the demography and energetics of Plectus palustris and Caenorhabditis briggsae at different food concentrations. They showed that the life history of both species is quite flexible. This flexibility itself is an adaptive trait, which differs between the two species. C. briggsae, which is limited (in nature) to very high bacterial densities, only grows optimally at the highest bacterial densities that were experimentally feasible. Its growth ceases at around $10^{8}$ bacteria $\mathrm{ml}^{-1}$, which is still a relatively high density.

$P$. palustris, on the other hand, survives at a bacterial density one order of magnitude lower. Its optimal food density is also lower. This corresponds to its occurrence, in nature, in less saprobic (although still quite enriched) environments.

Food quality is important, as nematodes appear to be selective in the food species they take up (e.g. Trotter and Webster 1984). Monhystera disjuncta did not grow on many potential food species occurring in its natural environment (Vranken et al. 1984). The reasons for this apparent selectivity were not clear. It is possible that some bacteria are indigestible by the limited array of enzymes synthesized by nematodes (Deutsch 1978). Alternatively, these bacteria may condition the agar medium adversely, or, finally, they may miss an essential growth factor for the nematodes. These last possibilities were tested by buffering the $\mathrm{pH}$ of the agar, and adding a sterol mixture to the medium (Vanfleteren 1980).

\section{Material and methods}

\section{Culture techniques}

Monhystera disjuncta was sampled in the Sluice Dock of Ostend, a marine lagoon near the Belgian coast. A few $\mathrm{ml}$ of sediment were inoculated in 4 spots, made in $14 \mathrm{~cm}$ diameter petri dishes with (DIFCO) bacto-agar (1\% in 
water from the natural habitat, see Vranken et al. 1981). After 1-2 weeks incubation, the nematodes (and other organisms) invade the agar surrounding the detritus spots. They were picked out of the agar individually to start the pure cultures.

Agnobiotic cultures were set up in small petri dishes (diameter $3.5 \mathrm{~cm}$ ) filled with $4 \mathrm{ml}$ of $0.4 \%$ bacto-agar. This agar was made up with Sluice Dock water and enriched with $1 \%$ Vlasblom medium $\left(0.278 \mathrm{~g} \mathrm{FeSO}_{4} \cdot 7 \mathrm{H}_{2} \mathrm{O}, 3.0 \mathrm{~g}\right.$ $\mathrm{NaHPO}_{4} \cdot 2 \mathrm{H}_{2} \mathrm{O}, 30.0 \mathrm{~g} \mathrm{NaNO}, 0.47 \mathrm{~g} \mathrm{MnCl}_{2} \cdot 4 \mathrm{H}_{2} \mathrm{O}$, $50.0 \mathrm{~g}$ glycine in $11 \mathrm{aq}$. dest.: Vlasblom 1963) and $0.5 \%$ of a $15 \mathrm{~g} / \mathrm{l}$ solution of $\mathrm{Na}_{2} \mathrm{SiO}_{3} \cdot 9 \mathrm{H}_{2} \mathrm{O}$. Salinity was controlled with a refractometer and kept between $29 \%$ and $31 \%$ by the addition of distilled water when necessary. The agar was inoculated with a few drops of paper-filtered water from the Sluice Dock. Bacteria grew rapidly on the medium.

After a few days the petri dishes were inspected. Dishes showing development of fungi were discarded. The rest was inoculated with adult $M$. disjuncta from the extraction plates.

At regular intervals these stock cultures were renewed by transferring at least 20 females and 10 males (preferably not all coming from the same old stock culture dish) to a new petri dish: 4-5 stock culture dishes were simultaneously kept. The Sluice Dock was routinely sampled and extraction dishes set up, so that wild animals could regularly be added to the laboratory stock.

The methods for the life table experiments in monoxenic cultures were extensively described by Vranken et al. (1985) and will only be summarized below. A bacterial strain belonging to the Alteromonas haloplanktis rRNA group, coded ISC2, was isolated from the Sluice Dock. It is depos. ited in the collection of the Laboratory for Microbiology, State University of Gent (Dir. Prof. De Ley), where it was identified. Bacterial suspensions were injected in a central ring in the sterile bacto-agar. The agar was only enriched with $5 \%$ sterol mixture, containing $10 \mu \mathrm{g} \mathrm{ml}^{-1}$ of cholesterol, stigmasterol, ergosterol, 7-dehydrocholesterol and sitosterol each; the cultures were buffered to $\mathrm{pH} 7.5-8.0$ by the addition of $0.005 \mathrm{M}$ TRIS buffer.

Nematodes were isolated from field samples as described above, axenised during $24 \mathrm{~h}$ in agar containing $10000 \mathrm{IU}$ penicillin and $10 \mathrm{mg} \mathrm{m}^{-1}$ streptomycine, and transferred to the monoxenic cultures.

Experiments with different bacterial strains were conducted in the same way. Bacterial strains were obtained from the Scottish collection of marine bacteria, Torry Research Station, Aberdeen, Scotland. The bacteria were incubated overnight in nutrient broth, separated by centrifugation, washed in artificial sea water, concentrated again by centrifugation and injected in the nematode culture dish.

For the life table experiments in excess-food monoxenic cultures, bacterial density in the suspension was $\geq 10^{11}$ cells $\mathrm{ml}^{-1}$.

Concentrations gradients of ISC2 were prepared by dilution of a stock suspension with a density of $10^{11}$ cells $\mathrm{ml}^{-1}$. Density was controlled with a Petroff-Hauser counting chamber. $20 \mu \mathrm{l}$ of a suspension of known density was added in the ring. In the monoxenic experiments, including those with varying food density, the nematodes were inoculated in the experimental dish when $3.5 \mathrm{~d}$ old. This allowed for a standardized density per dish. In the agnotobiotic cultures this factor was not standardized due to the cohort raising technique used: 20 to 50 adult females and 10 males were placed on a fresh culture dish. They deposited eggs until the next day when they were removed. The developing eggs constituted the experimental cohort.

\section{Estimation of the life history parameters}

Egg development time $(\mathrm{E})$, minimum generation time $\left(T_{\min }\right)$ of males and females, $\%$ hatching success, $\%$ juvenile (postembryonic) mortality, and sex ratio were determined simultaneously in 3-8 replicate experiments with a total of at least 100 individuals. $t_{0}$ is taken as halfway between the moments of introduction and removal of the adults that deposited the eggs constituting the cohort. Thus adults were removed at $t=0.5 \mathrm{~d}$.

The culture dishes were controlled daily, and the number of juveniles, mature (=egg-bearing) females and males recorded. All mature adults were removed from the culture dish to avoid confusion with the next generation.

Egg deposition rate was determined in several replicate cultures, each containing 1-3 females and 1-3 males. At least every 3 days the number of eggs was counted. Daily egg production was calculated as the mean number of eggs produced per female per day in the observation interval. Approximately every $T_{\min } / 2$ the adults were transferred to fresh cultures. The deposited eggs were followed until maturation, thus allowing a direct observation of the number of female offspring produced per female alive aged $x$. This observed value does not equal $m_{x}$, as it is lowered by embryonic and juvenile mortality.

However, by calculating the adult survival values relative to a value 1.0 at the onset of maturity, the $m_{x} l_{x}$ values are correct.

Age-specific survival values were determined in 3-4 replicate cultures, started with individuals aged $T_{\min }$.

Both sexes were kept together in the cultures, so as to keep the animals sexually active. They were transferred to new culture dishes every $T_{\min } / 2$ or sooner.

Following Gehan and Siddiqui (1973) a risk analysis was performed which compared several functional descriptions of the survival data: exponential, linear, Gompertz and Weibull functions. The Weibull distribution most often provided the best fit, although the Gompertz curve was in some instances slightly better. For uniformity, the Weibull distribution was fitted to all observed survival curves. The fitting method of Pinder et al. (1978), using double logarithmic transformation, was applied. The Weibull distribution is given by:

$N_{t}=N_{o} \exp \left(-(t / b)^{c}\right)$

where

$N_{t}=$ number of surviving organisms at time $t$

$N_{o}=$ number of organisms at the start of the experiment (age $T_{\min }$ ).

$c, b=$ constants to be fitted

$t=$ time from onset of the experiment

Survival values at each age $x$ were calculated from the fitted distribution, which provided an excellent fit in all cases. Mean adult longevity (MAL) was calculated as:

$\mathrm{MAL}=b \Gamma(1+1 / c)$

with $\Gamma$ the gamma function.

Given the products $m_{x} l_{x}$ at age $x$, the demographic variables $R_{0}, T_{c}$ and $r_{m}$ were calculated according to standard methods (see also Vranken and Heip 1983). 
Table 1. $M$. disjuncta in agnotobiotic culture: Mean development times, $95 \%$ confidence intervals, and number of animals observed for embryonic development (embr.), development to adult male and to adult female at 6 different experimental temperatures

\begin{tabular}{|c|c|c|c|c|c|c|c|c|c|}
\hline \multirow{2}{*}{$\begin{array}{l}\text { Tem- } \\
\text { perature }\end{array}$} & \multicolumn{3}{|c|}{ Embr. } & \multicolumn{3}{|c|}{ Female } & \multicolumn{3}{|c|}{ Male } \\
\hline & $\bar{x}$ & $\mathrm{CI}$ & $n$ & $\bar{x}$ & $\mathrm{CI}$ & $n$ & $\bar{x}$ & $\mathrm{CI}$ & $n$ \\
\hline $3^{\circ} \mathrm{C}$ & 9.8 & 0.2 & 490 & 52.3 & 1.0 & 287 & 47.6 & 1.2 & 158 \\
\hline $8^{\circ} \mathrm{C}$ & 5.1 & 0.2 & 115 & 18.6 & 1.0 & 56 & 16.9 & 1.1 & 33 \\
\hline $12^{\circ} \mathrm{C}$ & 3.5 & 0.1 & 956 & 17.2 & 0.3 & 662 & 15.8 & 0.5 & 245 \\
\hline $15^{\circ} \mathrm{C}$ & 2.9 & 0.1 & 375 & 11.8 & 0.3 & 241 & 11.7 & 0.4 & 71 \\
\hline $17^{\circ} \mathrm{C}$ & 2.9 & 0.1 & 1275 & 10.9 & 0.3 & 226 & 11.0 & 0.6 & 90 \\
\hline $20^{\circ} \mathrm{C}$ & 2.3 & 0.1 & 458 & 9.3 & 0.3 & 291 & 9.6 & 0.4 & 111 \\
\hline
\end{tabular}

Table 2. Monhystera disjuncta in agnotobiotic culture: parameters of the allometric relationships (development time $=a$ temp $^{-b}$ ) describing the dependence of embryonic development time (d), and of development time (d) to the adult female and adult male stages on temperature $\left({ }^{\circ} \mathrm{C}\right)$

\begin{tabular}{lrlll}
\hline Stage & $a$ & $b$ & SE $(b)$ & $r^{2}$ \\
\hline Embryonic & 23.75 & -0.76 & 0.051 & 0.88 \\
Female & 118.13 & -0.84 & 0.051 & 0.90 \\
Male & 108.19 & -0.82 & 0.053 & 0.89 \\
\hline
\end{tabular}

Table 3. Mean $T_{\min }$ (days) and $95 \%$ confidence interval of $M$. disjuncta fed eight different bacterial strains (monoxenic cultures at $17^{\circ} \mathrm{C}$ ). Each mean is based on four replicate cultures, each with 30 nematodes

\begin{tabular}{llllll}
\hline Bacterial strain & \multicolumn{2}{l}{ Females } & & \multicolumn{2}{l}{ Males } \\
\cline { 2 - 3 } & Mean & $95 \% \mathrm{CI}$ & & Mean & $95 \% \mathrm{CI}$ \\
\hline ISC2 & 7.35 & 0.15 & & 7.13 & 0.16 \\
E. coli & 8.41 & 0.24 & & 7.98 & 0.20 \\
Micrococcus sp. & 8.13 & 0.19 & & 8.17 & 0.24 \\
Ps. fluorescens & 7.81 & 0.23 & & 7.73 & 0.17 \\
Ps. marina & 7.82 & 0.19 & & 7.40 & 0.18 \\
KB1a1 & 7.62 & 0.19 & 7.43 & 0.18 \\
KB1a3 & 8.68 & 0.21 & 7.85 & 0.17 \\
KB1a5 & 7.61 & 0.22 & 7.65 & 0.20 \\
\hline
\end{tabular}

\section{Results}

The dependence of $T_{\min }$ on temperature in agnotobiotic culture was already discussed by Vranken and Heip (1986). It can be described by the allometric function:

$T_{\min }=a T^{-\mathrm{b}}$

where $T$ is temperature in ${ }^{\circ} \mathrm{C}$. This function can also be applied to describe the dependence of embryonic development time on temperature. Table 1 gives the mean values of embryonic development time and of $T_{\min }$ at different temperatures in the agnotobiotic cultures. The parameters of the allometric functions are given in Table 2. The basal temperature (biological zero) is implicitly assumed to be $0^{\circ} \mathrm{C}$ when this function is fitted. This is realistic for $M$. disjuncta. The lowest temperature we tried was $3^{\circ} \mathrm{C}$, but Gerlach and Schrage (1971) report a culture of $M$. disjuncta at between $-1^{\circ} \mathrm{C}$ and $+1^{\circ} \mathrm{C}$.

Apart from temperature, feeding conditions also influence $T_{\min }$. Table 3 gives the mean $T_{\min }$ at $17^{\circ} \mathrm{C}$ with differ-
Table 4. Monhystera disjuncta in monoxenic cultures at $17^{\circ} \mathrm{C}: \mathrm{AN}-$ OVA of mean development times with different bacterial strains as food sources. Mean development time of a sex in a replicate culture was used as the basic variable. Analysis is according to the completely randomized split-plot design, in which bacterial strains are the main plots, and sexes the subunits

\begin{tabular}{lrrrrl}
\hline Source of variation & df & SS & MS & F & \\
\hline Bacteria & 7 & 7.08 & 1.01 & 18.43 & $P<0.005$ \\
$\quad$ error & 24 & 1.32 & 0.05 & & \\
Sex & 1 & 1.14 & 1.14 & 23.92 & $P<0.005$ \\
Interaction & 7 & 1.29 & 0.18 & 3.85 & $P<0.01$ \\
$\quad$ error & 24 & 1.15 & 0.05 & & \\
Total & 63 & 11.98 & & & \\
\hline
\end{tabular}

Table 5. Mean $T_{\min }$ (days) and $95 \%$ confidence intervals of $M$ disjuncta fed 7 different densities of bacterial strain ISC2 in monoxenic cultures at $17^{\circ} \mathrm{C}$. Each mean is based on 4 replicate cultures, each with 30 nematodes. Also indicated is the \% of the inoculated nematodes that eventually matured. Up to 7.5 days of age, no mortality was observed in the cultures

\begin{tabular}{lccccccc}
\hline \multicolumn{7}{c}{ Bacterial Density } \\
\cline { 2 - 8 } & $10^{11}$ & $10^{10}$ & $5 \cdot 10^{9}$ & $10^{9}$ & $5 \cdot 10^{8}$ & $10^{8}$ & $10^{7}$ \\
\hline $\begin{array}{l}\text { Females } \\
\bar{x}\end{array}$ & 7.61 & 7.70 & 7.76 & 8.01 & 8.17 & 8.62 & 10.55 \\
CI & 0.10 & 0.14 & 0.15 & 0.26 & 0.28 & 0.41 & 0.62 \\
Males & & & & & & & \\
$\quad \bar{x}$ & 7.61 & 7.65 & 7.75 & 8.58 & 8.82 & 9.52 & 10.21 \\
CI & 0.07 & 0.10 & 0.14 & 0.36 & 0.36 & 0.44 & 0.60 \\
$\%$ Matured & 100.0 & 97.5 & 100.0 & 93.3 & 94.2 & 86.7 & 41.7 \\
\hline
\end{tabular}

ent bacterial strains as food. Analysis of variance (Table 4) demonstrates a significant effect of food type on $T_{\min }$. The sexes differ significantly in their development time. In general, males have a shorter development time, although this too seems to depend on food type (cf. significant interaction between food type and sex in Table 4).

Table 5 shows the influence of bacterial density (strain ISC2) on $T_{\min }$ at $17^{\circ} \mathrm{C}$. Analysis of variance (Table 6) shows a signficant effect of food density and sex, but no significant interaction between them. Down to a bacterial density of $5 \cdot 10^{8} \mathrm{ml}^{-1}$ virtually all nematodes matured, with a $T_{\min }$ only slightly influenced by food density. The few losses are animals which crawl out of the agar, stay in the water film at the border of the dish, and die there. They can be considered technically inevitable losses. However, at $10^{8}$ and (much more) at $10^{7}$ bacteria $\mathrm{ml}^{-1}$ part of the nematodes never mature. They live for a long time as juveniles, and eventually die before reaching adulthood. Consequently, they cannot be incorporated in the calculation of $T_{\min }$. The effect of food density on $T_{\min }$ seems relatively small, but this impression is, at least at $10^{7}$ bacteria $\mathrm{ml}^{-1}$, partially an artifact. The effect is similar in both sexes, resulting in a quite constant sex ratio in those animals that do mature.

Egg deposition rates were studied at $3^{\circ} \mathrm{C}, 12^{\circ} \mathrm{C}$ and $17^{\circ} \mathrm{C}$ in agnotobiotic culture, and at $17^{\circ} \mathrm{C}$ in monoxenic (high food density) culture on ISC2 (Fig. 1) Daily egg deposition is nearly constant in the first period following maturity. The length of this period depends on temperature and 

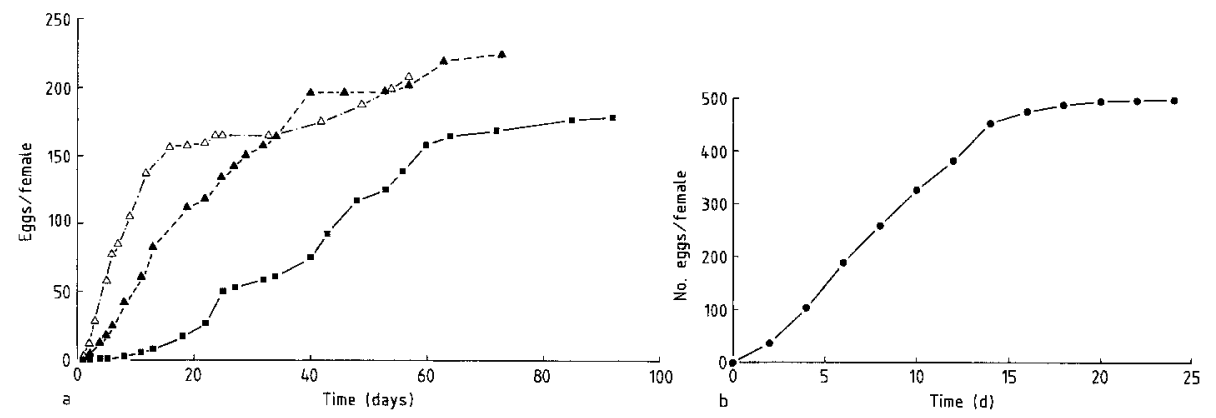

Fig. 1. Monhystera disjuncta: cumulative curves of egg deposition (number of eggs per female) vs. time in (a) agnotobiotic cultures at $3^{\circ} \mathrm{C}$ (closed squares), $12^{\circ} \mathrm{C}$ (closed triangles) and $17^{\circ} \mathrm{C}$ (open triangles), and (b) in high food density monoxenic cultures on ISC2 at $17^{\circ} \mathrm{C}$. Note differences of scale in the $\mathrm{Y}$ axis between the two graphs

Table 6. Monhystera disjuncta: ANOVA of mean development times with different bacterial densities of the strain ISC2 in monoxenic cultures at $17^{\circ} \mathrm{C}$. Same design as in Table 2

\begin{tabular}{lrrrrl}
\hline Source of variation & df & \multicolumn{1}{c}{ SS } & MS & F & \\
\hline Density & 6 & 56.09 & 9.35 & 21.74 & $P<0.005$ \\
$\quad$ error & 21 & 9.04 & 0.43 & & \\
Sex & 1 & 2.12 & 2.12 & 10.12 & $P<0.005$ \\
Interaction & 6 & 1.88 & 0.31 & 3.85 & ns \\
$\quad$ error & 21 & 4.40 & 0.21 & & \\
\cline { 2 - 6 } Total & 55 & 73.54 & & & \\
\hline
\end{tabular}

Table 7. Egg production of $M$. disjuncta (eggs/female day) 7 days after adulthood in monoxenic cultures at $17^{\circ} \mathrm{C}$, with different bacterial strains as food. Each mean is based on 4 replicate cultures with 30 nematodes each. The number of females in each culture is variable

\begin{tabular}{lll}
\hline Bacterial strain & Mean & St. err. \\
\hline ISC2 & 35.10 & 3.50 \\
E. coli & 39.50 & 3.60 \\
Micorococcus sp. & 35.00 & 3.90 \\
Ps. marina & 41.75 & 2.78 \\
Ps. fluorescens & 38.00 & 5.55 \\
KB1a5 & 20.00 & 0.91 \\
\hline
\end{tabular}

Table 8. Monhystera disjuncta. Demographic parameters in agnotobiotic culture at $3^{\circ} \mathrm{C}, 12^{\circ} \mathrm{C}$ and $17^{\circ} \mathrm{C}$, and in monoxenic culture on strain ISC2 at $17^{\circ} \mathrm{C}: R_{0}$ (dimensionless), $r_{m}$ (intrinsic rate of natural increase, $\mathrm{d}^{-1}$ ), $T_{0}$ (generation time, $\mathrm{d}$ ), egg production (number of eggs per female per day), pre-adult mortality (\%), and MAL (Mean Adult Longevity, d)

\begin{tabular}{lcccc}
\hline Parameter & \multicolumn{2}{l}{ Agnotobiotic } & ISC2 \\
\cline { 2 - 4 } & $3^{\circ} \mathrm{C}$ & $12^{\circ} \mathrm{C}$ & $17^{\circ} \mathrm{C}$ & $17^{\circ} \mathrm{C}$ \\
\hline$R_{0}$ & 111 & 123 & 102 & 302 \\
$r_{m}$ & 0.058 & 0.171 & 0.285 & 0.422 \\
$T_{0}$ & 80.8 & 28.1 & 16.2 & 13.5 \\
egg prod. & 2.7 & 5.1 & 9.2 & 32.3 \\
$T_{\text {min }}$ female & 52.3 & 17.2 & 10.9 & 8.1 \\
$\quad$ male & 47.6 & 15.8 & 11.0 & 8.0 \\
pre-ad. mort. & 23 & 14 & 8 & 8 \\
MAL female & 123 & 49 & 38 & 23 \\
$\quad$ male & 201 & 90 & 54 & - \\
\hline
\end{tabular}
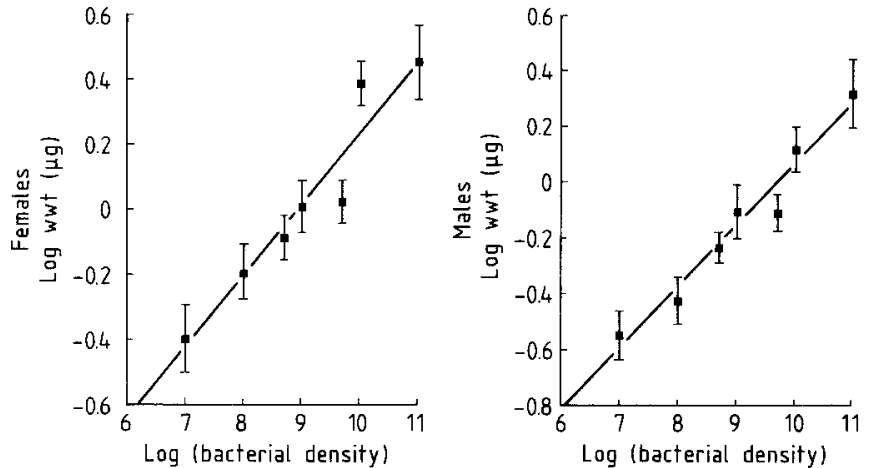

Fig. 2. Monhystera disjuncta: relation between body weight ( $\mu \mathrm{g}$ wet weight per individual) and bacterial density in the food suspension (strain $\mathrm{ISC} 2$ at $17^{\circ} \mathrm{C}$ )

food. Although egg production can continue afterwards for quite a long period, this is only a minor contribution to the total reproductive output. We estimated daily egg production as the slope of the linear regression of cumulative egg production on time, during the period that this function was linear.

Both temperature and food have highly significant effects on egg deposition $(P<0.001)$. In the cultures with different bacterial strains as food the egg deposition was checked 7 days after $T_{\min }$. The results are summarized in Table 7. Food quality had a significant effect $(0.005<P<$ 0.01 ). This effect is due to the low egg production with the KB1A5 strain (which is significantly lower than all the other strains: " $T$ " a posteriori test at the $5 \%$ level). The other strains were not significantly different from one another.

Adult survival was studied at $3^{\circ} \mathrm{C}, 12^{\circ} \mathrm{C}$ and $17^{\circ} \mathrm{C}$ in agnotobiotic culture and at $17^{\circ} \mathrm{C}$ in high density culture with ISC2. Temperature and food influence survival. In general, Mean Adult Longevity (MAL) (Table 8) is inversely correlated with egg production. Males live longer than females.

The above consequences of temperature and food are summarized in the demographic parameters (Table 8).

The influence of food density (strain ISC2) on adult body mass (measured the second day after maturation using Andrassy's (1956) formula) is shown in Fig. 2. Log (body mass) is a linear function of $\log$ (bacterial density), given by the equations:

$\log (\mathrm{W})=-1.955+0.219 \log (\mathrm{D})$ (females)

$\log (\mathrm{W})=-2.143+0.221 \log (\mathrm{D})$ (males) 
Table 9. Monhystera disjuncta: literature data on culture of the species. Indicated are the salinity $(\%)$, temperature $\left({ }^{\circ} \mathrm{C}\right)$ at which the cultures were held, and the minimum generation time (d) obtained (mean and range of the observations)

\begin{tabular}{llll}
\hline Salinity & Temp. & $T_{\min }(\mathrm{d})$ & Authority \\
\hline Seawater & $20-24$ & 30 & $\begin{array}{l}\text { Chitwood and Murphy } \\
(1964) \\
\text { von Thun (1968) }\end{array}$ \\
5 & $20-22$ & $23 \quad(18-28)$ & $\begin{array}{l}\text { Gerlach and Schrage } \\
(1971)\end{array}$ \\
32 & 26 & no growth & idem \\
32 & $17-22$ & $12 \quad(8-15)$ & idem \\
32 & $13-15$ & $15(9-20)$ & idem \\
32 & $9-12$ & $17(13-24)$ & idem \\
32 & 7 & $22(14-32)$ & idem \\
32 & $0-2$ & $78(77-81)$ & idem \\
32 & $-1-+1$ & $131(128-134)$ & \\
\hline
\end{tabular}

where $\mathrm{W}$ is adult wet weight in $\mu \mathrm{g}$ and $\mathrm{D}$ bacterial density (bacteria $\mathrm{ml}^{-1}$ ).

The regressions are highly significant $(\mathrm{F}=55.0$ and 50.7 resp., with 6 and $133 \mathrm{df} ; P<0.001$ ). Slight but significant deviations from linearity are observed $(P<0.001$ for females, $0.025<P<0.05$ for males). These are due to the low values observed at $5 \cdot 10^{9}$ bacteria $\mathrm{ml}^{-1}$.

\section{Discussion}

$M$. disjuncta has previously been cultured by von Thun (1968), Chitwood and Murphy (1964), Gerlach and Schrage (1971). $T_{\min }$ values in these studies are summarized in Table 9 . Whereas the values for $T_{\text {min }}$ obtained in earlier studies are considerably higher than our values, those of Gerlach and Schrage (1971) correspond extremely well with our equation which predicts $T_{\min }$ values of $9.73 \mathrm{~d}, 12.86 \mathrm{~d}$, $16.37 \mathrm{~d}, 23.01 \mathrm{~d}$ and $65.92 \mathrm{~d}$ at $19.5^{\circ} \mathrm{C}, 14^{\circ} \mathrm{C}, 10.5^{\circ} \mathrm{C}, 7^{\circ} \mathrm{C}$ and $2^{\circ} \mathrm{C}$ resp. In contrast to this good correspondence for $T_{\text {min }}$, Gerlach and Schrage (1971) find an egg production during her entire lifetime of only $37 \mathrm{eggs}^{\mathrm{female}}{ }^{-1}$ at $17-22^{\circ} \mathrm{C}$. This observation is puzzling. The development times indicate similar conditions for both (agnotobiotic) experiments. One would expect to find a similar egg production too, as development time and egg production are negatively correlated in our data set.

It was concluded by Vranken et al. (1984) that $M$. disjuncta is highly selective in its feeding habits, not being able to grow or reproduce on most bacterial strains offered. This conclusion became questionable after we observed that the addition of a sterol mixture and of TRIS buffer greatly improved the culture on ISC2, the only bacterial strain that allowed monoxenic culturing even without these additions.

The present experiments confirm that these factors, rather than the presumed selectivity, are responsible.

Addition of TRIS buffer, without sterols, allows $25-50 \%$ of the individuals (depending on the bacterial strain given as food) to mature, albeit only after approximately 15 days. With sterols but without buffer, only ISC2 allows growth of the nematodes. In the $E$. coli agar dish, the $\mathrm{pH}$ was as low as 3.7 after two days. $M$. disjuncta does not survive when $\mathrm{pH}$ is lower than approximately 6.5 .

Incidently, we discovered that the silicate solution added to the Vlasblom medium in the agnotobiotic cultures was only useful as a $\mathrm{pH}$ buffer.
Although there is a significant reduction in $T_{\text {min }}$ at high food concentrations, $M$. disjuncta is not as flexible in the regulation of its generation time as Caenorhabditis briggsae (Schiemer 1982a, b). With a (low) food density of $2 \cdot 10^{8}$ bacteria $\mathrm{ml}^{-1}$ the $T_{\min }$ of the latter species is more than three times as long as with a high food density $\left(10^{11}\right.$ bacteria $\mathrm{ml}^{-1}$ ). This factor is only 1.4 in our experiments. Probably we did not include the very limiting food density in the experimental series, although $M$. disjuncta did not survive at $5 \cdot 10^{6}$ bacteria $\mathrm{ml}^{-1}$, and at $10^{7}$ bacteria $\mathrm{ml}^{-1}$ only half the individuals reached adulthood.

On the other hand, we observe an enormous flexibility in the adult body mass of $M$. disjuncta. Adults reared at $10^{11}$ bacteria $\mathrm{ml}^{-1}$ are about 7 times as heavy as adults reared near the limiting food density. This is a much larger variability than in C. briggsae (Schiemer 1982a), where wet weight at $5 \cdot 10^{10}$ bacteria $\mathrm{ml}^{-1}$ is 1.4 times the wet weight at $5.10^{8}$ bacteria $\mathrm{ml}^{-1}$ (using our regression equations to interpolate, we arrive at a factor 2.74 for exactly the same range in $M$. disjuncta). In the agnotobiotic cultures both $T_{\min }$ and adult body weight were similar to those obtained at $10^{7} \mathrm{ISC}_{2} \mathrm{ml}^{-1}$.

Daily egg production rate in agnotobiotic cultures is 3.5 times lower than in optimal monoxenic cultures. The period of egg production is somewhat longer, resulting in a 3-fold difference in $R_{0}$. However, as $T_{\min }$ does not change very drastically, $r_{m}$ differs only by a factor 1.5 . The total production of a female during her lifetime (somatic and egg production) differs by a factor 3.75 .

Apparently, $M$. disjuncta is not as good in taking advantage of abundant food, as Caenorhabditis briggsae or even Plectus palustris. At high food density, a larger proportion of a female's production during her lifetime is chanelled into somatic production (around $30 \%$ at $10^{11}$ bacteria $\mathrm{ml}^{-1}$, compared with around $11 \%$ at $10^{7}$ bacteria $\mathrm{ml}^{-1}$, neglecting the somatic production from 2 days after maturation onwards in both cases). The larger body size does not result in higher survival probabilities (on the contrary, MAL is shorter) nor in a better viability of the eggs. It seems to be only a by-product of the fact that development into an adult takes a certain, relatively unflexible, minimum time. Extra energy becoming available during this period is chanelled into extra body mass, but without any apparent adaptive reason.

This could indicate that $M$. disjuncta is adapted to lower food levels in nature than the species studies by Schiemer (1983). The minimal concentration of bacterial carbon at which it can survive is $0.006 \mathrm{mg} \mathrm{dwt} \mathrm{ml} l^{-1}$. This is $1 / 4$ th of the value for $P$. palustris and $1 / 16$ th of that for $C$. briggsae. Nonetheless, $M$. disjuncta can maintain a relatively high $r_{m}$ at low food concentrations. $r_{m}$ in the agnotobiotic cultures is about equal to the $r_{m}$ of $P$.palustris in optimal culture conditions (the $r_{m}$ of $C$. briggsae in optimal conditions is 4 times higher).

Egg production rate too, does not seem to depend as strongly on food density as it does in C. briggsae. Adult body growth (i.e. body growth after maturation) is much more important in high food density cultures than in low density cultures (G. Vranken, personal observation). This may also be a by-product of a relatively fixed egg production rate: whereas somatic growth in the juvenile phase increases by a factor 7 over the density range studied, egg production rate increases only by a factor 3.5 .

In $M$. disjuncta, which seems to be adapted to a (rela- 
tively) lower food density regime, the proportion of egg production in the total (egg + somatic) production during a female's lifetime decreases with increasing food density.

The reverse is true for $C$. briggsae, where the proportion devoted to egg production raises from $76 \%$ to $84 \%$ over a food density range from $10^{8}$ to $10^{10}$. In $P$. palustris the proportion remains constant at about $70 \%$.

Although some species are more variable than others in their life history parameters, it is now clear that nematode populations are capable of considerable flexibility. Whether this flexibility is in itself adaptive, probably depends on the particular species. In species living in temporary environments, such as the polysaprobic C. briggsae, flexibility is very much needed. The species is only competitively superior at high bacterial densities (Schiemer 1983). It must be able to profit as much as possible of these circumstances. Probably for species normally living in less enriched environments, this extreme flexibility is less called for.

Flexibility is important if we want to draw general conclusions about energy transfer through nematode populations.from our culture data. Of course, this conclusion may be biased, since lab culturing methods tend to select for the most versatile ("weed") species. Anyway, we should keep this versatility in mind. In previous compilations (Heip et al. 1985; Vranken et al. 1986) we have used the agnotobiotic cultures as the best approximations of field conditions. How can we be sure about their validity? Comparison of bacterial densities in sediments with those in agar cultures is not useful as a basis for justification: individual size, nutritional value and availability to grazing of the bacteria may be very different. Thus we still remain in a situation where the characteristics of field populations are, at best, approximated by our cultures, but remain largely unknown.

In the meantime, generalizations such as given by Vranken et al. (1986), remain useful but also dangerous tools.

Acknowledgements. This research was supported through the Concerted Actions Oceanography of the Ministry of Scientific Policy, grant 2.9007.82 from the Fund of Collective Fundamental Research of Belgium and through grant ENV-767-B of the CEC. P. Herman and C. Heip acknowledge a grant from the Belgian National Fund for Scientific Research (NFWO). We thank Rudy Vanderhaeghen, Kris Verschraegen and Guido Mandelings for help with the cultures and observations.

\section{References}

Abrams BI, Mitchell MJ (1980) Role of nematode-bacterial interactions in heterotropic systems with emphasis on sewage sludge decomposition. Oikos 35:404-410

Alongi DM (1985a) Microbes, meiofauna, and bacterial productivity on tubes constructed by the polychaete Capitella capitata. Mar Ecol 23:207-208

Alongi DM 1985b) Effect of physical disturbace on population dynamics and trophic interactions among microbes and meiofauna. J Mar Res 43:351-364

Andrassy I (1956) The determination of volume and weight of nematodes. Acta Zool Acad Sci Hung 2:1-15

Chitwood BG, Murphy DG (1964) Observations on two marine Monhysterids - their classification, cultivation and behaviour. Trans Am Microsc Soc 83:311-329

Deutsch A (1978) Gut ultrastructure and digestive physiology of two marine nematodes, Chromadorina germanica (Butschli 1874) and Diplolaimella sp. Biol Bull 155:317-335

Findlay SEG, Tenore KR (1982) Effect of a free-living marine nematode (Diplolaimalla chitwoodi) on detrital carbon mineralization. Mar Ecol 8:161-166

Gehan EA, Siddiqui MM (1973) Simple regression methods for survival time studies. J Am Stat Assoc 68:848-856

Gerlach SA, Schrage M (1971) Life cycles in marine meiobenthos. Experiments at various temperatures with Monhystera disjuncta and Theristus pertenuis (Nematoda). Mar Biol 9:274-280

Heip C, Vincx M, Vranken G (1985) The ecology of marine nematodes. Oceanogr Mar Biol 23:399-489

Herman PMJ, Vranken G, Heip C (1984) Problems in meiofauna energy flow studies. Hydrobiologia 118:21-28

Klekowski RZ, Schiemer F, Duncan A (1979) A bioenergetic study of a benthic nematode, Plectus palustris de Man 1880, throughout its life cycle. Oecologia (Berlin) 44:119-124

Pinder JEIII, Wiener JG, Smith MH (1978) The Weibull distribution: a new method of summarizing survivorship data. Ecology 59:175-179

Schiemer F (1982a) Food dependence and energetics of free-living nematodes. I. Respiration, growth and reproduction of Caenorhabdits briggsae at different levels of food supply. Oecologia (Berlin) 54:108-121

Schiemer F (1982 b) Food dependence and energetics of free-living nematodes. II. Life history parameters of Caenorhabditis briggsae (Nematoda) at different levels of food supply. Oecologia (Berlin) 54:122-128

Schiemer F (1983) Food dependence and energetics of free-living nematodes. III. Comparative aspects with special consideration of two bacterivorous species Caenorhabditis briggsae and Plectus palustris. Oikos $41: 32-43$

Schicmer F, Duncan A, Klekowski RZ (1980) A bioenergetic study of a benthic nematode Pelodera palustris de Man, 1880, throughout its life cycle. Oecologia (Berlin) 44:205-212

Thun W von (1968) Autökologische Untersuchungen an freilebenden Nematoden des Brackwassers. Diss. Kiel, p 72

Tietjen JH (1980) Microbiol-meiofaunal interrelationship: a review. In: Microbiology 1980. VIII. Conf. Amer. Soc. Microbiol on Ecology, Feb. 7-10, 1979, Clearwater Beach, Florida. Amer Soc Microbiol, Washington, DC, USA, pp. 335-338

Trotter D, Webster JM (1984) Feeding preferences and seasonality of free-living marine nematodes inhabiting the kelp Macrocystis integrifolia. Mar Ecol 14:151-157

Vanfleteren JR (1980) Nematodes as nutritional models. In: Zuckerman BM (ed) Nematodes as biological models, vol 2. Academic Press, New York, pp 47-79

Vlasblom AG (1963) Het schelpdierlarvenonderzoek in het laboratorium te Wemeldinge van 11 juli $1955-31$ juli 1963. Internal report, $218 \mathrm{pp}$

Vranken G, Heip C (1983) Calculation of the intrinsic rate of natural increase, $r_{m}$ with Rhabditis marina Bastian 1963 (Nematoda). Nematologia 29:468-477

Vranken G, Heip C (1986) The productivity of marine nematodes. Ophelia 26:429 442

Vranken G, Thielemans L, Heip C, Vandycke M (1981) Aspects of the life-cycle of Monhystera parelegantula (Nematoda, Monhysteridae). Mar Ecol 6:67-72

Vranken G, Van Brussel D, Vanderhaeghen R, Heip C (1984) Research on the development of a standardized ecotoxicological test on marine nematodes. I. Culturing conditions and criteria for two Monhysterids, Monhystera disjuncta and Monhystera microphthalma. In: Persoone G, Jaspers E, Claus (eds) Ecotoxicological testing for the marine environment, vol 2. State University of Ghent and Inst. Mar. Scient. Res., Bredene, Belgium, pp. 159-184

Vranken G, Vanderhaeghen R, Heip C (1985) Toxicity of cadmium to free-living marine and brackish-water nematodes (Monhystera microphthalma, Monhystera disjuncta, Pellioditis marina). Dis aquat org 1:49-58

Vranken G, Herman PMJ, Vincx M, Heip C (1986) A reevaluation of marine nematode productivity. Hydrobiologia 135:193-196

Received April 15, 1988 